\title{
Endovascular aortic repair of Kommerell diverticulum associated with aberrant left subclavian artery
}

\author{
Anna K. Gergen ${ }^{1}$, Robert A. Meguid ${ }^{1,2}$, T. Brett Reece ${ }^{1}$ Muhammad Aftab $^{1}$ \\ ${ }^{1}$ Division of Cardiothoracic Surgery, Department of Surgery, University of Colorado Anschutz Medical Center, Aurora, CO, USA; ${ }^{2}$ Adult and Child \\ Consortium for Health Outcomes Research (ACCORDS), Aurora, CO, USA \\ Correspondence to: Muhammad Aftab, MD, FACS. Assistant Professor in Cardiothoracic Surgery, Division of Cardiothoracic Surgery, Department of \\ Surgery, University of Colorado Anschutz Medical Center, 12631 E. 17th Avenue, MS C-302, Aurora, CO 80045, USA. \\ Email: muhammad.aftab@cuanschutz.edu.
}

Submitted Apr 27, 2021. Accepted for publication Oct 13, 2021.

doi: 10.21037/acs-2021-taes-11

View this article at: https://dx.doi.org/10.21037/acs-2021-taes-11

\section{Clinical vignette}

A 62-year-old male presented with shortness of breath, dysphagia, and an unintentional 20-pound weight loss over the last three months. Computed tomography (CT) of the chest revealed a right-sided aortic arch with four branching arch vessels and a $3.5 \mathrm{~cm}$ Kommerell diverticulum at the origin of the aberrant left subclavian artery. The distal arch and proximal descending aorta were located posterior to the trachea and esophagus with obvious compression of the esophagus due to the Kommerell diverticulum and vascular ring. Esophagogram and upper endoscopy demonstrated focal compression of the upper thoracic esophagus by the Kommerell diverticulum. The patient was scheduled for a multidisciplinary, staged repair involving three separate procedures: left carotid-subclavian bypass, thoracic endovascular aortic repair (TEVAR), and finally left videoassisted thoracoscopic surgical (VATS) division of the aberrant left subclavian artery and vascular ring.

\section{Surgical techniques}

After undergoing a left carotid-subclavian bypass, the patient returned to the operating room the next day for TEVAR with coverage of the left subclavian artery origin and Kommerell diverticulum. Access to bilateral common femoral arteries was obtained and systemic heparin was administered. A diagnostic aortogram demonstrated the expected arch anatomy with four branching arch vessels, a patent left carotid-subclavian bypass, and the known Kommerell diverticulum at the origin of the aberrant left subclavian artery. Intravascular ultrasound of the aortic arch and descending thoracic aorta was performed to evaluate the branch vessels and proximal and distal landing zones.

Next, the right femoral sheath was exchanged for a 20 -French sheath. A $40 \times 40 \times 150 \mathrm{~mm}^{3}$ thoracic stent graft was passed through the sheath into the aortic arch. The graft was then deployed to its first stage just distal to the right subclavian artery with subsequent retraction on the inner curve control wires to pull the curve in and down to fit the sharp angled arch. The graft was then fully deployed with contraction on the active control strings to pull the graft down onto the tight inner arch with good positioning. The stent graft was ballooned and completion aortogram demonstrated a well-positioned stent graft approximately $1.5 \mathrm{~cm}$ distal to the right subclavian artery along the greater curvature. The left subclavian artery origin was covered with no filling of the Kommerell diverticulum. The right common femoral artery was closed with a percutaneous vascular closure device and protamine was administered. The patient was extubated and taken to the intensive care unit in stable condition.

The next day, the patient was taken back to the operating room for the final stage of the repair. The patient was intubated with a dual-lumen endotracheal tube and positioned in the right lateral decubitus position. The left chest was entered via the 7 th intercostal space anterior axillary line. Two additional working ports were placed with one inferior and posterior to the scapular tip and the other in the 4th intercostal space anterior axillary line. The left lung was isolated from the ventilator and retracted 
caudally. The mediastinum was examined and an aberrant torturous-appearing structure was identified. The left phrenic nerve was identified and traced along the anterior aspect of this structure. The overlying pleura was incised with electrocautery and gentle blunt dissection was used until an arterial structure was identified. Circumferential control of the vessel was achieved with a suture. A gold load Endo-GIA stapler was placed across the vessel and clamped without change in the patient's left-sided cuff pressure. The artery was then divided. The proximal end of the divided artery was dissected free from the surrounding tissue proximally to ensure the Kommerell diverticulum was free from attachments with no remaining vascular ring. Endoscopy confirmed a widely patent esophagus with no evidence of external compression. An intercostal nerve block was performed, a 28 -French chest tube was placed into the left hemithorax, and incisions were closed. At 15-month follow-up, the patient reported complete resolution of symptoms with follow-up CT imaging demonstrating a well-positioned stent graft with thrombosis of the Kommerell diverticulum.

\section{Comments}

Right-sided aortic arch with aberrant left subclavian artery is a rare congenital anomaly affecting up to $0.5 \%$ of the population (1). Aneurysmal degeneration at the origin of the aberrant subclavian vessel results in a Kommerell diverticulum. This may be asymptomatic or cause significant symptoms from tracheal or esophageal compression related to the growing aneurysm and vascular ring created by the location of the aberrant vessel and ligamentum arteriosum. Furthermore, a Kommerell diverticulum may predispose to more serious complications such as aortic aneurysm, dissection, or rupture. Historically, open repair to resect the aneurysmal segment and replace with an interposition graft followed by left arm revascularization was the surgical method of choice. More recently, minimally invasive and endovascular approaches to repair have gained traction as they avoid the morbidity of a thoracotomy or sternotomy incision as well as the need for aortic cross-clamping or hypothermic circulatory arrest (2-4).

We have demonstrated that use of an endovascular technique to exclude the diverticulum and promote eventual thrombosis of the remnant is a safe and feasible approach to the management of Kommerell diverticulum. Furthermore, our approach is unique in that we describe a comprehensive repair strategy that addresses left arm revascularization, coverage of the Kommerell diverticulum to eliminate risk of degeneration and rupture, and thoracoscopic division of the aberrant vessel and vascular ring to alleviate associated compressive symptoms. Complete division of the vascular ring is a critical step to achieving long-lasting symptom relief. Disadvantages to our staged repair include repeated visits to the operating room, which could increase time in the hospital and overall cost. However, this sequential approach is necessary in order to fully address the pathology and symptoms at hand. Additionally, combining stages of the repair into a single surgery may be possible in specific subsets of patients, particularly when the risk of diverticular rupture is low. In patients with Kommerell diverticulum and associated compressive symptoms, we conclude that a hybrid endovascular approach involving subclavian artery revascularization, TEVAR to exclude the diverticulum, and VATS division of the aberrant subclavian vessel and vascular ring is a safe, well-tolerated, and durable alternative to the conventional open technique.

\section{Acknowledgments}

Funding: None.

\section{Footnote}

Conflicts of Interest: The authors have no conflicts of interest to declare.

Open Access Statement: This is an Open Access article distributed in accordance with the Creative Commons Attribution-NonCommercial-NoDerivs 4.0 International License (CC BY-NC-ND 4.0), which permits the noncommercial replication and distribution of the article with the strict proviso that no changes or edits are made and the original work is properly cited (including links to both the formal publication through the relevant DOI and the license). See: https://creativecommons.org/licenses/by-nc-nd/4.0/.

\section{References}

1. Cinà CS, Althani H, Pasenau J, et al. Kommerell's diverticulum and right-sided aortic arch: a cohort study and review of the literature. J Vasc Surg 2004;39:131-9.

2. Idrees J, Keshavamurthy S, Subramanian S, et al. Hybrid repair of Kommerell diverticulum. J Thorac Cardiovasc 
Surg 2014;147:973-6.

3. Hayakawa M, Nagano T, Nishijima I, et al. Successful Endovascular Repair of a Kommerell's Diverticulum and a Right-Sided Aortic Arch. Heart Surg Forum 2020;23:E860-2.

Cite this article as: Gergen AK, Meguid RA, Reece TB, Aftab M. Endovascular aortic repair of Kommerell diverticulum associated with aberrant left subclavian artery. Ann Cardiothorac Surg 2021;10(6):807-809. doi: 10.21037/acs-2021taes-11
4. Ghincea CV, Ikeno Y, Weyant MJ, et al. Right Thoracoscopic Aberrant Right Subclavian Artery Division and Subclavian-Carotid Transposition. Ann Thorac Surg 2020;110:e431-3. 